\title{
CAMINHOS DE LIBERDADE: QUATRO MOMENTOS DO GRUPO “CÁRCERE, EXPRESSÃO E LIBERDADE"
}

\author{
Ana Gabriela Mendes Braga ${ }^{1}$ \\ Isadora Thomaz Ribeiro \\ José Eduardo Adami de Jesus ${ }^{3}$
}

\begin{abstract}
Resumo
Este artigo propõe pensar a extensão universitária como vaso comunicante e vivo com a comunidade que, portanto, deve ser afetada e afetar o seu redor. Propomos analisar a trajetória do grupo Cárcere, Expressão e Liberdade (C.E.L) em relação ao contexto sociopolítico em que se desenvolve extensão, no nosso caso, o sistema prisional. Daremos destaques às mudanças e provocações no contexto, a partir de quatro momentos da nossa trajetória. Para tanto, utilizamos o histórico dos relatórios das atividades do grupo como fonte para pensar e retomar o transcurso do grupo. Ao final, propomos diretrizes para extensão, e destacamos a importância da universidade no cárcere.
\end{abstract}

Palavras-chave: Cárcere. Comunicação. Extensão.

\begin{abstract}
This article proposes to think of university extension as a communicating and living vessel with the community that, therefore, must be affected and affect its surroundings. We propose to analyze the trajectory of the group Cárcere, Expressão e Liberdade (C.E.L) in relation to the socio-political context in which extension takes place, in our case the prison system. We will highlight the changes and provocations in the context from four moments of our trajectory. To do so, we use the history of the reports of the group activities as a source to think and resume the course of the group. In the end, we propose guidelines for extension, and importance of the university in prison.
\end{abstract}

Keywords: Prison. Communication. Extension.

\section{Introdução}

Investigar o sistema penal no Brasil, em seus mais diversos âmbitos, por meio da pesquisa ou extensão, é caminhar sobre um solo de profundas desigualdades. Assim, é preciso estar de olhos atentos para a seletividade, repressividade e estigmatização que sustentam os discursos e práticas penais. Procuramos, de modo constante, ter cuidado com os passos seguidos, pois nesse solo irregular, a areia movediça é capaz de cooptar e engolir anseios de

\footnotetext{
${ }^{1}$ Professora de Direito Penal da Universidade Estadual Paulista (UNESP), Faculdade de Ciências Humanas e Sociais, Franca-SP; Doutora em Criminologia pela USP; Coordenadora do Grupo Cárcere, Expressão e Liberdade (CEL).

${ }^{2}$ Graduanda do $5^{\circ}$ ano de Direito da UNESP, integrante do Grupo CEL.

${ }^{3}$ Graduando do $3^{\circ}$ ano de Direito da UNESP, integrante do Grupo CEL.
} 
crítica e transformações radicais. Para que tal investigação seja realizada com fulcro na realidade, "não pode o jurista encerrar-se no estudo - necessário, importante e específico, sem dúvida - de um mundo normativo, ignorando a contradição entre as linhas programáticas legais e o real funcionamento das instituições que as executam" (BATISTA, 2015, p. 26)

Deste modo, pensar a execução da pena privativa de liberdade e aquilo que gravita em seu redor nos pareceu um campo a ser explorado e o papel da criminologia crítica está justamente em trazer para o centro do debate as faces mais turvas e discricionárias desse ambiente. Como bem explana Batista:

\footnotetext{
Ao contrário da criminologia tradicional, a criminologia crítica não aceita, a qual a priori inquestionável, o código penal, mas investiga como, por quê e para quem (em ambas direções: contra quem, e em favor de quem) se elaborou este código e não outro. (...) procura verificar o desempenho prático do sistema penal, a missão que efetivamente lhe corresponde, em cotejo funcional e estrutural com outros instrumentos formais de controle social (...) A criminologia crítica insere o sistema penal - e sua base normativa, o direito penal - na disciplina de uma sociedade de classes historicamente determinada e trata de investigar, no discurso penal, as funções ideológicas de proclamar um igualdade e neutralidade desmentidas pela prática. (2015, p. 32).
}

Diante dos processos de massificação do encarceramento, é necessário travar uma luta pela manutenção de garantias de direitos, inclusive daqueles não suprimidos pela pena de privação de liberdade, como dispõe a própria Lei de Execução Penal, tendo o exemplo da precariedade na aplicação do instituto da remição por meio do estudo e trabalho. Contudo, essa luta não pode se afastar do horizonte de desconstrução de práticas punitivas. Vale pontuar que o Brasil acaba de despontar como a terceira maior população carcerária do mundo (cerca de 726 mil aprisionados), sendo o estado de São Paulo responsável por 33,1\% da população carcerária total do país (BRASIL, 2017, p.9).

Nesse contexto, no ano de 2001, surge o grupo de extensão Cárcere, Expressão e Liberdade (CEL), propondo uma ponte dialógica entre a realidade universitária e o cárcere. Respeitando as especificidades desafiadoras do sistema prisional, é necessário estarmos atentos para as consequências deste trabalho para o próprio sistema, por isso, prezamos por uma construção pedagógica que tenha raízes na horizontalidade, almejando, em nossos espaços de diálogo, contrapor a lógica vertical e discricionária, tão característica dessas instituições. 
A Universidade Pública deve pensar na construção de um conhecimento que esteja em conexão com a realidade social e articular a pesquisa e a extensão de forma a favorecer a emancipação da população que financia a existência do ensino superior público no estado de São Paulo. Na prática extensionista, erige-se a necessidade de explorar frentes de atuação, coordenando apontamentos teóricos que guiam discursos e práticas críticas ao pensamento punitivista. $\mathrm{Na}$ busca para concretizar um diálogo sincero entre academia e comunidade, o Grupo CEL se debruça na construção de uma luta crítica ao sistema penal instituído e integra uma rede local de organizações com objetivos comuns.

Assim, buscamos, aqui, tratar de como o grupo se estruturou ao passar dos anos, os métodos de atuação, as reviravoltas e suas reações, diante de alicerces que intentam subverter a lógica punitivista. Buscamos, também, mostrar quais os caminhos percorridos para a efetivação da extensão universitária como um vaso comunicante entre a prisão, a academia e a comunidade; e, ainda, aquilo que se logrou e que se busca aperfeiçoar por meio de ações que se idealizam na atualidade.

Este artigo percorre quatro momentos importantes da história do grupo, com ênfase nos últimos dois anos de atuação: começamos com o inicio do grupo e o trabalho de quinze anos nas prisões de mulheres da região (Extensão na prisão de mulheres); em seguida, narramos nossa chegada à penitenciária masculina (Deslocando-se no campo). Em um terceiro momento; contamos participação do grupo na construção do Conselho da comunidade local (Construindo portas); e, mais recentemente, o desenvolvimento do projeto de remição por leitura (Asas da liberdade). Ao final, propomos pensar a extensão e esses quatro momentos como vasos comunicantes da prisão e da universidade.

\section{Extensão na prisão de mulheres}

O Grupo Cárcere, Expressão e Liberdade nasceu em 2001, como Projeto Cadeia, a partir da demanda observada por funcionários e estagiários do Centro Jurídico Social - Unidade Auxiliar da UNESP -, que presta assistência jurídica e social gratuita para a população de baixa renda da cidade de Franca - SP. O Projeto Cadeia iniciou sua atuação na Cadeia Pública Feminina de São José da Bela Vista, cidade vizinha. O objetivo era primariamente socioeducativo, promovendo a realização de oficinas artísticas e de capacitação.

Contudo, a principal necessidade das mulheres presas logo mostrou ser o acesso às informações processuais e os caminhos para suas liberdades. Para contemplar essa carência, o Projeto passou a fazer, também, o acompanhamento processual, para aliviar a ansiedade e a 
obscuridade do andamento de seus processos, assim como a orientação jurídica para sanar dúvidas e municiá-las de conhecimento.

A cadeia de São José da Bela Vista, entretanto, bem como a maioria do sistema carcerário, era mantida de forma precária. Em 2006, a insalubridade chegou a níveis críticos, gerando uma denúncia no jornal local pela situação da prisão. Haviam 46 mulheres presas em 3 celas planejadas para abrigar 15 pessoas. As condições de higiene eram absurdas, com proliferação de sarna e piolho. De acordo com Cicliani (2006), não tinham chuveiros e lavavam louça na pia do banheiro. Depois da denúncia, a Vigilância Sanitária verificou essas e outras irregularidades e o laudo ocasionou o fechamento da cadeia. As mulheres foram transferidas, então, para a Cadeia de Batatais, como aponta Toledo (2006).

O Projeto Cadeia continuou sua atuação em Batatais nos mesmos moldes. O próximo marco importante de sua história foi a desvinculação do Centro Jurídico Social, que já não atendia mais casos criminais. O Projeto já tinha condições de caminhar sozinho e, portanto, ganhou autonomia no ano de 2009. Em 2010, foi construído, em Franca, o Centro de Detenção Provisória Masculino, o que levou a outra realocação do Projeto. As mulheres foram transferidas de Batatais para a Cadeia Pública do bairro Guanabara, em Franca, recém esvaziada, em virtude da mudança dos homens que ali se encontravam para o CDP.

Durante sua história, o Projeto teve dificuldade em se ater a seu objetivo socioeducativo inicial, devido à inexistência do efetivo acesso à justiça. Além de desconhecerem os trâmites processuais, a maioria não recebia a devida atenção e orientação de seus advogados ou defensores, e o grupo acabava as suprindo. Por ser uma cadeia e não penitenciária, quase todas as mulheres estavam presas provisoriamente, aguardando julgamento. A sensação era de se estar num limbo: nem livres, nem condenadas. A espera indefinida era psicologicamente torturante.

Quando condenadas, eram transferidas. A rotatividade era outro entrave para nossas atividades: tínhamos que reapresentar o Projeto várias vezes durante o ano e perdíamos integrantes assíduas frequentemente. Por isso, dificilmente conseguíamos manter um grupo por tempo suficiente para fixarmos sentimentos de identificação e pertencimento, essenciais para a troca aberta e horizontal.

Por vezes, elas decidiam não participar de nossas atividades, crendo que sairiam logo; destino da minoria delas. Pudemos presenciar o cumprimento de alguns raros alvarás de soltura, protagonistas das cenas mais emocionantes que vivenciamos dentro da prisão. Assim que 
anunciada a saída de uma das mulheres encarceradas, todas as outras vibravam de felicidade e empatia, abraçavam-na e a desejavam boas coisas. Cantavam em uníssono uma canção sobre liberdade e saudade que ecoava pelas celas e pelo pátio.

Apesar das dificuldades, não desistimos. Em 2014, o Projeto Cadeia se reestruturou e passou a se chamar Grupo Cárcere, Expressão e Liberdade (C.E.L.). Visando recuperar a intenção fundamental, deixamos para trás o acompanhamento processual, e focamos nas dinâmicas, debates e manifestações artísticas que abordassem temas sociopolíticos relevantes.

Levamos a ideia de publicarmos nossas experiências como grupo (universitários e presas) em um blog, e elas abraçaram prontamente. Algumas escreveram relatos honestos sobre suas trajetórias para compor o blog, contando sobre suas vidas antes e durante a prisão. Outras compuseram poesia. Essa forma de comunicação extramuros foi muito valorizada por essas mulheres, que sempre tiveram suas vozes cerceadas pela dupla opressão que as aflige: do sistema penal e da condição de gênero. Muitas delas, também, pela questão racial.

Tendo isso em vista, buscamos, por meio da horizontalidade, criar um espaço aberto à reflexão crítica, possibilitando o empoderamento, a construção dialógica de conhecimento coletivo e a descoberta do posicionamento de todos como sujeitos históricos e políticos. Nesse sentido, versa Freire:

(...) a comunicação verdadeira não nos parece estar na exclusiva transferência ou transmissão do conhecimento de um sujeito a outro, mas em sua coparticipação no ato de compreender a significação do significado. Esta é uma comunicação que se faz criticamente. (FREIRE, 2014, p. 47). O diálogo é o encontro amoroso dos homens que, mediatizados pelo mundo, o 'pronunciam', isto é, o transformam, e, transformando-o, o humanizam para a humanização de todos (FREIRE, 2014, p. 28)

\section{Deslocando-se no campo: a chegada no cárcere masculino}

Antes mesmo do repentino fechamento da Cadeia Pública Feminina de Franca, o grupo tencionava alcançar novos ambientes para enfrentar os processos de encarceramento que se manifestavam ao redor. Em nossa cidade, estava localizado o Centro de Detenção Provisória, construído em 2010, que, recentemente, fora transformado em Penitenciária pelo Decreto Estadual $\mathrm{n}^{\circ}$ 62.762. Sua capacidade, segundo dados da Secretaria de Administração Penitenciária (SAP) do Estado de São Paulo, é para 847 homens, entretanto, em consulta à 
página virtual da SAP, a população se concentrava em 2012 encarcerados em 24 de junho de 2018. (SÃO PAULO, 2018)

Nossa entrada se deu a partir da articulação do grupo com a Diretoria de Reintegração Social, que se demonstrou aberta a uma nova construção daquele ambiente. Tínhamos, nesse momento, o privilégio de ter uma membra do grupo, discente do curso de Serviço Social, realizando atividades de estágio ali, o que proporcionou uma facilitação de tais contatos.

Apresentamos nosso projeto junto à Diretora de Reintegração para o Diretor Geral da penitenciária e, assim, conseguimos autorização para iniciarmos nossos trabalhos em uma frequência quinzenal, com cerca de 30 homens em situação de cárcere. Infelizmente, não nos foi informado como estes membros seriam selecionados, ficando turva essa questão ainda hoje.

O primeiro dia naquele ambiente guarda sensações muito potentes em cada extensionista que viveu esse momento. A estrutura era muito distinta daquilo que tínhamos passado na cadeia feminina: grandes portões de ferro azul, gaiolas e mais gaiolas, detector de metais e revistas separavam o "mundão" daqueles primeiros contatos.

Nossas atividades foram e seguem sendo realizadas no bloco da escola, e ali estavam presentes universitários, o corpo de assistência social da Diretoria de Reintegração e 30 rostos de desconhecidos que, conforme o tempo, foram ganhando personalidades muito marcantes. Vimos que, neste primeiro momento, algumas arestas não estavam aparadas entre os objetivos do grupo e administração, que embutia anseios que não eram compatíveis com nossa base teórica. Assim, um clima desconfortável e apreensivo nos foi gerado. A sorte é que encontramos na Diretora de Reintegração uma abertura dialógica que proporcionou, conforme as atividades que se seguiam, um alinhamento, que atualmente, comemoramos.

O ciclo de atividades proposto era de se discutir e dinamizar temáticas que perpassam a experiência no cárcere e nossas experiências de vida, para criar, juntos, por meio desse canal de comunicação, um conhecimento que fosse tangível às realidades ali dispostas. Assim, realizou-se um enfrentamento ao hermetismo forçado da instituição prisional, ambiente em que a supressão de direitos e a violência se travestem de lidimidade. Dessa forma, nosso instrumento revolucionário era, por muitas as vezes, construir espaços que invertessem a lógica recrudescida dessa instituição, cumprindo com o que é discutido por Braga (2015):

A abertura de diálogo entre a comunidade e a prisão pode flexibilizar o fechamento característico da instituição prisional, possibilitando assim a redução do impacto da 
prisão sobre a vida do condenado e de todos que de alguma forma se relacionam com ele. Portanto, uma diminuição qualitativa do encarceramento. (BRAGA, p. 91, 2015).

Isso era percebido em momentos em que, ao nos despedirmos nos dias de nossas atividades, éramos tocados por comentários que diziam sobre o esquecimento de estar privado de liberdade naquelas 3 horas que passávamos ali. Diferentemente de nossas experiências anteriores, despertar uma discussão era extremamente fácil, logo, pudemos tratar de questões como família, estigma, trabalho, reintegração social, violência, entre outras temáticas que figuravam em nossas comunicações.

Uma das atividades mais produtivas foi a dinâmica que realizamos para dialogar sobre gênero. Esse foi um desafio que arriscamos em construir. Prezando pela horizontalidade em nossas relações, sempre estávamos dispostos a discutir temas propostos por eles, e, assim, sentimos que poderíamos experimentar tratar de questão ainda tão delicada. O "ser homem" e o "ser mulher" foram ilustrados com três caixas ao centro de uma roda, em uma delas demarcado mulher, outra, homem, e, entre as duas, uma neutra, em que se retiravam figuras, palavras, comandos, que deviam ser colocados com coisa masculina ou feminina. A discussão perpassou questões religiosas, certa confusão entre gênero e sexualidade, porém, ainda assim, percebemos uma curiosidade em relação à questão e, por muitas vezes, uma relativização dos padrões que percebemos tão arraigados em nossos contatos sociais. Um deles pontuou que, entre tantas coisas ali colocadas que costumamos ouvir ser "coisa de mulher", somente "batom" seria algo exclusivamente feminino.

É difícil transpor em palavras as diversas experiências que pudemos trocar ali, diálogos valorosos foram coroados após seis meses de atividades. Naquele ambiente, já existiam laços construídos, apego pelas formas de comunicação que havíamos estabelecido e muitos diziam não aceitar o encerramento do ciclo. Com a entrega dos certificados de participação, ainda resistem na memória e nos relatórios internos do grupo dizeres em relação à exposição do documento aos familiares.

Ao fim, levamos tintas e um tecido para confecção de uma bandeira, e muitos assinaram seus nomes, suas cidades, adornados com desenhos e muitas cores. Entretanto, não há quem tenha passado ileso de um dos momentos mais emocionantes que pudemos perceber enquanto universidade ali, um membro pediu a palavra e nos presenteou com uma poesia de sua autoria: 
Quero aqui nestas palavras agradecer a todos vocês!! Que deixaram seus afazeres para compartilhar seus conhecimentos e nos compreender..

Muitos dizem que não há solução, mas com suas palavras vemos que temos recuperação.

Recuperar nossa dignidade e nos tornarmos verdadeiros cidadãos Como muitos disseram, não vai ser fácil, lá fora a maioria irá nos julgar pelo o que fomos, mas há pessoas diferentes que assim como vocês nos trazem a reflexão para entrarmos na sociedade e resolvermos essa questão, que para tudo há reabilitação. Reabilitar nossa mente e coração, para vivermos em harmonia com a sociedade e mostrar que tudo há solução, basta apenas transformar nossa mente e coração

Obrigado por compartilhar essa experiência, por mostrar que nesse mundo ainda existe amor com o próximo, e isto é um dom, um dom que vem de Deus!!!

Obrigado a todos vocês!!! (GLAJ, 2017)

\section{Construindo portas: o Conselho da Comunidade sobre sistema carcerário}

A experiência extensionista no interior da Penitenciária Masculina de Franca - SP motivou um significativo reenquadramento do olhar para a prisão. A estrutura, os contatos e as disputas ideológicas exigiram uma mobilização massiva daqueles que integravam o grupo enquanto universidade. Com o decorrer de nosso primeiro ciclo de atividades, novos caminhos foram possíveis e um esboço de rede de enfrentamento aos processos locais de massificação do encarceramento parecia se delinear.

Surge, então, a construção de um novo vaso comunicante entre a sociedade local e o cárcere, o Conselho da Comunidade sobre sistema penitenciário. Em observância da Lei $n^{\circ}$ 7.210 de 1984 (LEP) e seu artigo $4^{\circ}$, o Estado deve recorrer à cooperação da comunidade nas atividades de execução da pena e medida de segurança. Assim, o mesmo texto legal ostenta, em seus artigos 80 e 81, a composição e incumbências de tal órgão, instituindo-o como um componente da execução penal. Percebe-se, todavia, sua pouca efetivação nas comarcas do país, ainda que possua um gama considerável de potencialidades. Segundo orientação de cartilha emitida pelo Departamento Penitenciário Nacional:

(...) promover a aproximação da comunidade com a prisão e da prisão com a comunidade, por meio do Conselho da Comunidade, pode favorecer o desvelamento e o enfrentamento de esquemas que originam e reforçam a criminalidade, que se encontram no seio da própria sociedade. É necessário compreender que a prisão e as pessoas lá detidas integram a mesma sociedade em que vivemos, e não um mundo à parte sobre o qual nada temos a ver, os Conselhos da 
Comunidade operam como um mecanismo para esse reconhecimento e para que a sociedade civil possa efetivamente atuar nas questões do cárcere, quer para humanizálo, quer para que as pessoas que lá estão possam retornar ao convívio social a partir de uma perspectiva mais reintegradora. (BRASIL, 2008, p.9).

Essa construção, originou-se de uma reunião realizada no Centro de Referência em Assistência Social (CRAS - Leste) para que o grupo pudesse, junto à Diretora de Reintegração Social da penitenciária local, abordar as novas atividades que se desenvolviam. Ali, foram apresentadas as propostas e objetivos do grupo, mas, também, foi um espaço de críticas consistentes em relação à administração penitenciária.

Para compor aquele ambiente, estavam presentes o Conselho da Condição Feminina da cidade e mulheres que tinham familiares encarcerados e, assim, relatos sobre a supressão de direitos, que atinge diretamente famílias e pessoas encarceradas, motivaram uma proposição que partiu de um dos membros de nossa extensão: a criação do conselho da comunidade para pensar a prisão local e favorecer a reintegração social. Percebeu-se, então, uma perspectiva de caminho a ser traçado, e um diálogo entre entidades locais foi gerando reuniões de formação.

A Defensoria Pública entrou no projeto, trazendo uma consistência para os contatos que foram se efetivando com a secretaria de educação local, entidades educacionais e profissionalizantes, a Comissão de Direitos Humanos da Ordem dos Advogados da cidade, entre outros componentes dessa rede de comunicação.

Construir um conselho dessa forma exige certos estraves burocráticos, mas, desde o segundo semestre de 2017 até os dias de hoje, reuniões mensais de formação vêm sendo realizadas, como forma de alinhar perspectivas e projeções para o futuro funcionamento desse espaço. Nesse meio, surgiram um estatuto e uma mesa diretora, para cumprimento das devidas solenidades institucionais. Entretanto, o ponto alto desse processo de formação, que se desenvolve com a participação do grupo e cadeira garantida entre a base do conselho, é a possibilidade de contato com esses familiares que se comunicaram ou se comunicam com o cárcere de alguma maneira. São massivamente mães, esposas, que atuam fortemente para garantir o abastecimento material da prisão e a articulação das instituições estatais em favor de seus filhos ou companheiros, em situação de cárcere. Segundo Godoi (2015),

No estado de São Paulo, para quem está preso, a proximidade da família condiciona a experiência da pena, não só pelos vínculos afetivos que permite sustentar, mas 
porque incide positivamente em seus aspectos legais e materiais. Por outro lado, a própria experiência das pessoas que visitam parentes presos que procuram saber sobre os seus processos, tentam provocar movimentações processuais, levam jumbos e enviam Sedex informa sobre o funcionamento intestino da prisão, sobre suas particulares formas de gestão. (GODOI, 2015, p. 179).

Contamos, ainda, com a participação de egressos do sistema penitenciário que contribuem sobremaneira em todas as discussões ali realizadas. Afinal, enquanto integrantes da universidade, esses contatos fazem pensar não somente a atuação de um espaço que busque soluções que subvertam a superficialidade dos comuns debates relacionados à reintegração social, mas é, também, uma forma de construir um conhecimento acadêmico que perpasse e perceba a realidade dessas personagens.

\footnotetext{
A academia deve, neste sentido, pensar alternativas para o enfrentamento dos graves problemas gerados por uma política criminal vulnerabilizante, estigmatizante, encarceradora e punitiva. Deve propor uma nova política integrativa, que se preocupe com o indivíduo e se emancipe das categorias tradicionais criadas pela própria criminologia e pelo direito penal. (BRAGA, 2015, p. 111).
}

Almeja-se, então, a construção de uma rede que atue de forma crítica ao encarceramento instituído e, ao lidar com a materialidade, atue na fiscalização das práticas discricionárias características dos projetos não declarados da pena, assim como a extensão da prisão em seus vasos comunicantes. O Conselho da Comunidade sobre administração penitenciária seria um exemplo daquilo que se constrói diante do encarceramento, privilegiando uma análise que abarca as relações em que os muros da prisão se encontram diluídos no espaço.

\section{Asas da liberdade: projeto de remição por leitura}

A Remição é um estatuto previsto na LEP - Lei $n^{\circ} 7.210 / 84$ - que possibilita ao condenado reduzir o tempo de permanência na prisão. Conforme previsto no art. 126, caput, todo condenado que cumpre a pena em regime fechado ou semiaberto tem direito de remir, tanto por trabalho como por estudo, parte do tempo de execução da pena. O Projeto de lei $n^{\circ}$ 208/2017 pretende incluir em tal artigo da LEP a regulamentação da remição da pena do preso ou condenado pela leitura: 
Art. 126. O preso ou o condenado que cumpre a pena em regime fechado ou semiaberto poderá remir, por trabalho, estudo ou leitura, parte do tempo de execução da pena. (BRASIL, 2018)

Tal projeto objetiva inserir na lei as diretrizes do Conselho Nacional de Justiça (CNJ) para esse modelo de remição, conforme a Recomendação CNJ n 44, de 26 de novembro de 2013, que versa a respeito de modalidades de atividades educacionais complementares para fins de remição da pena pelo estudo e estabelece especificações e orientações para a admissão pela leitura, visando ampliar as possibilidades de educação e remição nas prisões:

Art. $1^{\circ}$ Recomendar aos Tribunais que:

[...] V - estimular, no âmbito das unidades prisionais estaduais e federais, como forma de atividade complementar, a remição pela leitura, notadamente para apenados aos quais não sejam assegurados os direitos ao trabalho, educação e qualificação profissional, nos termos da Lei n. 7.210/84 (LEP - arts. 17, 28, 31, 36 e 41, incisos II, VI e VII) [...] (BRASIL, 2018).

No âmbito das penitenciárias federais, o Ministro Corregedor-Geral da Justiça Federal e o Diretor do Departamento Penitenciário Nacional construíram a Portaria Conjunta ${ }^{\circ} 276$, de 20 de junho de 2012, pontuando critérios gerais para implementação da remição por leitura. Já na esfera Estadual, o Tribunal de Justiça de São Paulo, em sua unidade regional do departamento estadual de execuções criminais da $6^{\mathrm{a}}$ região administrativa, considerando a legislação posta sobre remição por leitura, instituiu apontamentos para remição por leitura, mediante portaria $\mathrm{n}^{\circ} 02$ de 2017, assinada pelo magistrado responsável Luís Augusto Freire Teotônio.

Partindo do arcabouço jurídico no tocante à remição por leitura, o Grupo foi provocado, até mesmo, pela administração penitenciária local a efetivar um projeto nesses moldes. A ideia já era existente na Cadeia Pública Feminina quando conseguimos efetivar a revitalização da biblioteca local, entretanto, a transitoriedade, os entraves burocráticos e fechamento brusco não possibilitaram sua concretização.

Em 2018, apresentamos, então, um projeto que pudesse efetivar a remição e dialogar com os objetivos já marcados em nossa prática no decorrer do tempo. Para nós, as discussões ocorridas naquele espaço eram imperiosas e poder atuar concretamente pela liberdade daqueles membros encarcerados era também necessário, assim, construímos uma tentativa de articular tais pontos. 
A administração penitenciária local deu seu aval e, neste ano, estamos construindo essa nova possibilidade de atuação. Incialmente, tencionamos trabalhar com um mesmo grupo por um ano e, assim, conseguirmos uma remição relevante para suas penas. Cada livro lido e resenhado proporciona 4 dias a menos no ambiente prisional, além de contatos com a literatura que, segundo relatos, proporcionam, por vezes, uma fuga de realidade tão difícil.

A cada mês, temos um título que encontramos a partir de expectativas de discussões e, também, de indicações daqueles que compõem o grupo de dentro do cárcere. Assim, são levadas as obras na primeira terça-feira de cada mês e, a partir disso, propomo-nos a discutir temáticas que perpassam a narrativa e que dialoguem com as experiências apresentadas na roda. Depois, há um hiato de uma semana para que possam avançar na leitura. Na terceira terça-feira do mês, voltamos para explorar mais minuciosamente aquilo que foi lido, as personagens, espaço, momentos marcantes, para, assim, na última semana, termos o desenvolvimento de uma resenha individual mais consistente e que, posteriormente, percorrerá os trâmites para a aprovação.

Este é um momento de experimentação. Construímos um projeto que exige que o grupo se debruce ainda mais na teoria educacional, para que os contatos de construção mútua de conhecimento possam se efetivar em uma ponte horizontal. Para isso, encontramo-nos duas vezes ao mês na universidade para debatermos autores que possam embasar esse processo e, ainda, dialogar sobre as limitações, desafios e inquietudes que despontam nesse período de novos passos.

\section{Considerações Finais}

A vivência extensionista na prisão derruba o senso comum do cárcere como um espaço hermético, fechado às influências externas, impermeável. Pelo contrário, a prisão é elemento social, que interfere e é interferida pela sociedade livre, sendo sustentada pelas relações criadas a partir de sua existência.

Apesar disso, a prisão segue com seu projeto de neutralização, tecendo grades físicas e imateriais que envolvem suas personagens como uma bolha. A cultura punitivista que alimenta nosso sistema de justiça contribui para uma visão "meritocrática" do sofrimento. Entende-se que aqueles que delinquem, independentemente da infração ou gravidade, são inimigos sociais. Essa noção, equivocada por si só, ainda é apoiada numa confiança temerária no sistema de justiça criminal. Como estudantes universitários, especialmente no curso de Direito, alienar-se da realidade carcerária traz consequências perturbadoras. É por meio da extensão que 
recorremos a outras fontes de conhecimento, não para substituir o acadêmico, mas para se somar.

Nas palavras de Godoi, "pode ser considerado um vaso comunicante toda forma, meio ou ocasião de contato entre o dentro e o fora da prisão. Trata-se de uma articulação particular que, ao mesmo tempo, une duas dimensões da existência social e define uma separação fundamental entre elas" (2015, p. 73). Nesse sentido, como extensionistas, procuramos reconhecer essa separação fundamental, na medida em que não somos alvos da seletividade penal e estamos sendo formados para fazer parte da outra face do sistema.

Para além do impacto nos indivíduos de fora, há o impacto nos indivíduos de dentro. $\mathrm{Na}$ prisão, lugarejo de inércia e desesperança, não é pequena qualquer tentativa de ruptura com a rotina: a comunicação horizontal é recebida com surpresa e apreço; a proposição de diálogos livres encoraja a expressão e a criticidade; a valorização de opiniões instiga a autoestima e o empoderamento pessoal e social. Num ambiente em que prevalece a padronização, infantilização e desumanização de corpos, tais esforços são legítimos.

Por fim, destacamos a extensão como vaso comunicante da prisão com a universidade, e, logo, com a sociedade. Não conseguiremos alterar o sistema de justiça atual sem uma mudança cultural. É crucial o fomento de discussões acerca de formas alternativas de resolução de conflitos sociais, independentes do encarceramento. Buscamos, também, quebrar paradigmas que enxergam a punição como medida adequada e justa. Acreditamos, portanto, na comunicação viva como ferramenta de crescimento, emancipação e transformação social, principalmente em um espaço de morte como nossas prisões.

\section{Referências}

BATISTA, Nilo. Introdução Crítica ao Direito Penal Brasileiro. 12 ed. Rio de Janeiro: Revan, 2011. $2^{\mathrm{a}}$ reimpressão, março de 2015.

BRAGA, Ana Gabriela Mendes. Reintegração Social: discursos e práticas na prisão - um estudo comparado. Tese (Doutorado). Faculdade de Direito da Universidade de São Paulo, 2012.

BRASIL. Lei $n^{\circ}$ 7.210, de 11 de julho de 1984. Lei de Execução Penal. Disponível em: <http://www.planalto.gov.br/ccivil_03/leis/L7210.htm>. Acesso em: 11 jan. 2018. 
BRASIL. Ministério de Justiça. Levantamento Nacional de Informações Penitenciárias: Atualização Junho de 2016. Organização, Thandara Santos; colaboração, Marlene Inês da Rosa. Departamento Penitenciário Nacional, Brasília: 2017. Disponível em: 〈http://justica.gov.br/news/ha-726-712-pessoas-presas-no-brasil/relatorio_2016_junho.pdf> Acesso em: 12 de mai. 2018.

BRASIL. Comissão para Implementação e Acompanhamento dos Conselhos da Comunidade. Cartilha Conselhos da Comunidade. Brasília: Ministério da Justiça, Departamento Penitenciário Nacional, 2008.

BRASIL. Conselho da Justiça Federal. Portaria Conjunta no 276 de 20 de junho de 2012. Disponível em:<http://www.cjf.jus.br/cjf/documentos/portaria_remissaopelaleitura.pdf/view $>$ Acesso em: 2 de jul. 2018.

BRASIL. Conselho Nacional de Justiça. Recomendação $N^{o} 44$ de 26/11/2013. Disponível em: < http://www.cnj.jus.br/busca-atos-adm?documento=1235> Acesso em: 2 de jul. 2018.

BRASIL. Ministério de Justiça. Levantamento Nacional de Informações Penitenciárias: Atualização Junho de 2016. Organização, Thandara Santos; colaboração, Marlene Inês da Rosa. Departamento Penitenciário Nacional, Brasília: 2017. Disponível em: <http://justica.gov.br/news/ha-726-712-pessoas-presas-no-brasil/relatorio_2016_junho.pdf> Acesso em: 20 de jun. 2018.

BRASIL. Senado. Projeto de Lei do Senado $n^{\circ} 208$, de 2017. Disponível em: <https://www25.senado.leg.br/web/atividade/materias/-/materia/129787> Acesso em: 2 de jul. 2018.

CICILIANI, Gabriel. Cadeia Feminina de São José abandono e superlotação. GCN, Franca, 28 dez. 2006. Disponível em: <http://gen.net.br/noticias/12006/franca/2006/12/cadeiafeminina-de-s-atilde0-j0s-eacute-aband0n0-e-superl0ta-ccedil-atilde0-12006>. Acesso em 25 jun. 2018. 
FREIRE, Paulo. Extensão ou comunicação? Editora Paz e Terra, 2014.

GODOI, Rafael. Fluxos em cadeia: as prisões em São Paulo na virada dos tempos.

Tese (Doutorado) - Departamento de Sociologia, Faculdade de Filosofia, Letras e Ciências Humanas, Universidade de São Paulo, São Paulo, 2015.

SÃO PAULO. Secretaria de Administração Penitenciária. Unidades Prisionais (penitenciárias). Disponível em: <http://www.sap.sp.gov.br/>. Acesso em: 23 mar. 2018.

TOLEDO, Melissa. Presas de São José festejam a conquista de um `novo lar`. GCN, Franca, 30 dez. 2006. Disponível em: <http://gcn.net.br/noticias/12150/franca/2006/12/presas-de-satilde0-j0s-eacute-festejam-a-c0nquista-de-um->. Acesso em 25 jun. 2018. 